\title{
Hospital based analytic study of peptic ulcer disease in patients with dyspeptic symptoms
}

\author{
Sharma SK ${ }^{1}$, Maharjan DK' ${ }^{2}$ Thapa PB $^{3}$
}

${ }^{1}$ Associate Professor, ${ }^{2}$ Lecturer, ${ }^{3}$ Assistant Professor, Department of Gastrointestinal and Endoscopic Surgery, Kathmandu Medical College, Sinamangal, Nepal

\begin{abstract}
Background: Peptic ulcer disease is one of the most common diseases prevalent in developing country like Nepal and with availability of endoscopy there have been increase in diagnosis and therapeutic use of endoscopy.

Objective: The aim of this study is to investigate the prevalence of peptic ulcer disease in patient who came for upper gastrointestinal endoscopy in Kathmandu Medical College Teaching Hospital.

Materials and methods: All patients who were referred to department of endoscopy from outpatient department (OPD) and inpatient department with symptoms like dyspepsia, upper GI bleeding were included from August 2004 to August 2008.

Results: A total of 2761 patient were evaluated, with mean age group of 40.57 years (range 8 - 95 years) and with sex distribution of male 1353 (49\%) and female 1408 (51\%) and racial difference into Aryan 2050 (74.2\%) and Mongoloid 771 (25.8\%). There were 983 patients (35.60\%) with peptic disease which includes erosive gastritis, non erosive gastritis, duodenitis and gastroduodenitis without obvious ulcer. The prevalence of peptic disease with or without ulcer was more common in age group of $20-49$ years $(n=764,27.67 \%)$ with 70 patient with gastric ulcer $(2.5 \%)$ and 50 patient with duodenal ulcer (1.8\%). There was no significant racial difference among incidence of peptic ulcer $(\mathrm{P}$ value $=0.527)$. Conclusions: Peptic ulcer disease is a significant cause of morbidity in urban population of Nepal with more prevalent of erosive diseases in productive age group (20-49 years). However both male and female have equal incidence of peptic ulcer disease and there was no significant racial difference in its incidence.
\end{abstract}

Key words: Peptic ulcer diseases, Oesophago-gastroduodenoscopy, H. pylori

$\mathrm{P}^{\mathrm{c}}$ eptic ulcer disease is still an important cause of morbidity and mortality in developing countries though its prevalence has shown decrease in developed countries $^{1}$. Almost $5-15 \%$ of adult population of world are suffering from peptic ulcer disease and its consequences $^{2}$ and in Nepal it is considered as the 7 th commonest cause of morbidity ${ }^{3}$. Though prevalence of duodenal ulcer have been significantly decrease by $50 \%$ than in past ${ }^{4}$, its incidence seems to be in still alarming trend in developing countries.

Many etiological factors have been labelled for cause of peptic ulcer disease including NSAID's and Helicobacter pylori as major causes. Besides, few studies have shown, male gender and elder age group are independent risk factors for peptic ulcer disease though correlation is yet not known ${ }^{5}$. There are also studies where prevalence is different according to race or geographical variations ${ }^{6}$. Endoscopic diagnosis of peptic ulcer and its consequences are getting more than before due to more availability of diagnostic services, increase in affordability of health services and increase in level of health education than before in urban areas.
The aim of our study is to investigate the prevalence and characteristics of peptic ulcer disease in an urban population and to analyse age, sex and racial variation of its incidence among them who were referred for an upper GI endoscopy in our institutions.

\section{Materials and methods}

All patients who were referred to endoscopy unit, Kathmandu Medical College Teaching Hospital from August 2004 to August 2008 were analysed .Patient were referred for dyspeptic symptoms (defined as intermittent epigastric pain or discomfort) and upper gastrointestinal bleeding. All information was obtained by a single investigator from patient charts, endoscopy, and pathology reports. Standard questionnaire was filled before endoscopy and entered into the reporting system,

\footnotetext{
Correspondence

Assoc. Prof. Sunil Kumar Sharma

Department of Gastrointestinal and Endoscopic Surgery,

Kathmandu Medical College Teaching Hospital, Sinamangal,

Kathmandu, Nepal

E-mail: samknp@yahoo.com
} 
together with endoscopic findings after endoscopy. The clinical information included patient age and gender, major indication for upper endoscopy, duration of the symptoms; Endoscopic information included current endoscopic diagnosis, lesion site, size and number. Biopsy was taken if suspicious lesion was seen and sent for histopathology examination. In selected patient whose dyspeptic symtoms were not responding to four weeks of proton pump inhibitors, biopsy was taken for H. pylori on repeat endosocpy .

Patients with $H$. pylori-positive peptic disease were treated with triple therapy consisting of Omeprazole $1 \mathrm{mg} / \mathrm{kg}$ /day twice a day (maximum $40 \mathrm{mg} /$ day) with Metronidazole $400 \mathrm{mg} 15 \mathrm{mg} / \mathrm{kg} /$ day twice a day (maximum $500 \mathrm{mg}$ b.i.d.) and Amoxicillin $50 \mathrm{mg} /$ $\mathrm{kg}$ /day twice a day (maximum $1000 \mathrm{mg}$ b.i.d.) for 7-10 days followed by Omeprazole $1 \mathrm{mg} / \mathrm{kg} /$ day twice a day (maximum $40 \mathrm{mg}$ /day) for at least 4 weeks.

Patients with $H$. pylori-negative peptic disease were treated with Omeprazole $1 \mathrm{mg} / \mathrm{kg} /$ day twice a day (maximum $40 \mathrm{mg} /$ day) for 4-6 weeks. Improvement was regarded as resolution or improvement of initial presenting symptoms.

\section{Functional definitions}

Peptic ulcer disease was defined as the presence of a clear-cut ulcer in either the stomach or duodenum. Ulcer was defined as a $\geq 5$-mm mucosal break in largest dimension, with depth. Erosive disease was defined as small superficial mucosal breaks not fulfilling the definition of an ulcer ${ }^{7,8,9}$.

\section{Statistical Analysis}

Statistical analysis was made using 13.0 version of SPSS for Windows software package (SPSS, Chicago, IL, USA). The chi-square ( $v 2)$ test and Fisher's exact probability test were applied for the prevalence of gastric and duodenal ulcers between different age, sex, and race, or when appropriate, correlation analysis was done. P - Value $<0.05$ was considered statistically significant.

\section{Results}

The main results of the study are presented in Table 1 . A total of 2761 patient were evaluated, with mean age group of 40.57 years (range 8- 95 years) and with sex distribution of male 1353 (49\%) and female 1408 (51\%) and racial difference into Aryan 2050 ( $74.2 \%$ ) and Mongoloid 771(25.8\%). There were 983 patients (35.60 $\%)$ with erosive disease and $177(6.5 \%)$ patient with peptic ulcer having active or healed gastric ulcer (2.6 $\%$ ) or duodenal ulcer (3.9\%) including 13 patient with gastric outlet obstruction due to deformed duodenal bulb. Gastric cancer and oesophageal cancer were confirmed with histological finding and were recorded in cancer registry of the hospital.

In all patient who were referred for upper GI Endoscopy, $1044(37.8 \%)$ had normal endoscopic finding ( Figure 1). Since majority of the patient were either referred from OPD or inpatient department form all departments for evaluation of pain abdomen or hematemesis or melena in order of frequency of symptoms they presented, so it has been used in this hospital as part of screening purpose for upper gastrointestinal pathology.

\section{Age and Peptic ulcer Disease}

The prevalence of peptic disease with or without ulcer was more common in age group of 20- 49 years $(n=$ $764,27.67 \%$ ) as shown in Figure 2.Peptic ulcer was more common in this age group including duodenal ulcer $(n=70,2.5 \%)$ and gastric ulcer $(n=50,1.8 \%)$ ,however there was no significant differnece $(\mathrm{p}$ - value : 0.657)

Similarly, erosive disease is more common in age group of 20-49 years $(n=644,23.32 \%) 1$ than above 50 years. So this shows that both peptic ulcer disease and erosive disease is common in age group of 20-49 years.

\section{Gender and Peptic ulcer Disease}

Amongst total 2761 patient male were 1353 (49\%) and female were 1408 (51\%). However, prevalence of duodenal ulcer is more common in male $(n=62,4.5 \%)$ than in female $(n=43,3.05 \%)$. Besides prevalence of gastric ulcer in both the sex were same, male $(n=36)$, female $(n=36)$. There was no statistically significant difference in incidence of peptic ulcer disease in both the group. (p - Value: 0.150). Beside 495 male (36.5\%) had erosive disease in comparison to 519 female (36.8\%) $(\mathrm{p}-$ value $=0.05)$.

\section{Race and peptic ulcer disease}

Out of 2761, Aryans were $2050 \quad(74.2 \%$ while Mongoloids were 711 (25.8\%). Duodenal ulcer was more prevalent in Aryans $(\mathrm{n}=78,3.8 \%)$ than in Mongoloids $(n=27,3.7 \%)$ and similarly gastric ulcer was more prevalent in Aryans $(n=53,2.5 \%)$ than in Mongoloids $(\mathrm{n}=19,2.6 \%)$.However, there was no significant differnce between two races. $(\mathrm{p}-$ value $=$ 0.052)

\section{H. pylori Status}

Diagnostic procedure for $H$. pylori is not done as routine procedure in Kathmandu Medical College. However during annual screening study conducted by Nippon Medical School in 2004-2005, amongst 369 biopsy only 203 were $H$. pylori positive and 166 were negative. Among them more male were H. pylori positive than female. The prevalence of duodenal ulcer 
and gastric ulcer in $H$. pylori positive patient were 2.4 $\%$ and $1.35 \%$, respectively.

\section{Discussion}

Peptic ulcer disease is known to be common in Nepal but there are very few reliable epidemiological data. Most of the study are from single hospital based study or private clinic evidence, however no study is present with community based study to know about its epidemiology. According to study done by Matsuhisa et al in 2005, amongst peptic ulcer disease $75 \%$ develops duodenal ulcer in urban population of Kathmandu. While $H$. pylori infection rate is around $54 \%$ amongst this population which was almost similar as that of Japanese population ${ }^{10}$. There was no racial difference in prevalence of $H$. pylori infection between Aryan and Mongolian races.

In the present study, incidence of gastric ulcer was equal in both sexes however incidence of duodenal ulcer is more common in male than female. Similar to our study, Peptic ulcer disease has been reported to occur more frequently in men than in women by some studies ${ }^{11,12,13,14}$ but not by other ${ }^{15,16}$. However, the pathophysiology for higher prevalence of Peptic ulcer disease in men is yet not clear. It may be related with higher incidence of smoking and alcoholism in male in Nepalese culture as many other studies have shown that cigarette smoking is associated with duodenal ulcer ${ }^{17,18}$. However data entry regarding smoking habits was partially filled in data registry so we were not able to include it.

The prevalence of peptic ulcer has been shown to increase with age till 50 years as noted in this study. Similarly studies have shown that prevalence of gastric ulcer increased with age in both male and female patients however, the prevalence of duodenal ulcer increased with age only in female patients, not in male patients ${ }^{19}$, in our study duodenal ulcer and gastric ulcer increased along with age till 50. However, erosive disease was much common in age group of $20-40$ years. This might be attributed to smoking and stress.

Though no national epidemiological studies have been conducted in Nepal regarding prevalence of peptic ulcer disease in different races which is primarily divide into Aryans and Mongoloids. According to our study both the races have equal prevalence of peptic ulcer disease with duodenal: gastric ulcer ratio of 1.47:1 than Mongoloids where duodenal: gastric ulcer ratio is 1.42:1(p - value: $0.527)$. There are studies signifying racial differences in prevalence of peptic ulcer diseases ${ }^{20-22}$ however factors attributing for it are yet unidentified. It would be of interest to look after food habits and lifestyle patterns among these two races in terms of prevalence of peptic ulcer disease.
Though diagnostic test for H.pylori is not routinely conducted in this hospital, among 369 biopsies for H.pylori during this study period, 203 were H. pylori positive and 166 were negative. And more male were H. pylori positive than female. The prevalence of duodenal ulcer and gastric ulcer in $H$. pylori positive patient were $2.4 \%$ and $1.35 \%$, respectively. Beside, $H$. pylori infection is also seen in healthy, asymptomatic individuals ${ }^{23}$. Even in our study $40.4 \%$ of $\mathrm{H}$. pylori positive patient were normal without any significant pathology.

In conclusion, peptic ulcer disease is equally prevalent in both the gender, however it increase along with age with peak incidence in age group of 20-49 years and there is no racial difference in terms of duodenal: gastric ulcer ratio between Aryans and Mongoloids. and H. pylori infection is common in this community.

\section{References}

1. Kang JY, Elders A, Majeed A et al. Recent trends in hospital admission and mortality rates for peptic ulcer in Scotland 1982-2002. Aliment Pharmacol Ther . 2006; 24: 65-79.

2. Everhart JE, Byrd-Holt D, Sonnenberg A. Incidence and risk factors for self-reported peptic ulcer disease in the United States. Am J Epidemiol .1998; 147: 529-36.

3. Ministry of Health and Population (MOHP) Nepal DoHS. Annual Report 2062/63 (2005/2006). Nepal: Ministry of Health and Population. 2008. p 135-54.

4. Xia B, Xia HH, Ma CW, Wong KW, Fung FM, Hui CK, et al. Trends in the prevalence of peptic ulcer disease and Helicobacter pylori infection in family physician-referred uninvestigated dyspeptic patients in Hong Kong. Aliment Pharmacol Ther. 2005; 22(3): 243-9.

5. Hui-Chao Wu, Bi-Guang Tuo, Wei-Min Wu, Yuan Gao, Qing-Qing Xu, Kui Zhao. Prevalence of Peptic Ulcer in Dyspeptic Patients and the Influence of Age, Sex, and Helicobacter pylori Infection. Dig Dis Sci. 2008; 53: 2650-6.

6. Katelaris PH, Tippett GHK, Norbu P, Lowe DG, Brennan R, Farthing MJG. Dyspepsia, Helicobacter pylori, and peptic ulcer in a randomly selected population in India. Gut. 1992; 33:1462-6.

7. Feldman M, Cryer B, Mallat D, Go MF. Role of Helicobacter pylori infection in gastroduodenal injury and gastric prostaglandin synthesis during long term/low dose aspirin therapy: a prospective placebo-controlled, double-blind randomized trial. Am J Gastroenterol. 2001; 96:1751-72. 
8. Dohil R, Hassall E. Gastritis, gastropathy and ulcer disease. In: Wyllie R, Hyams JS, eds. Pediatric Gastrointestinal and Liver Disease. 3rd ed. Philadelphia: Saunders. Elsevier, 2006. p 373-408.

9. 9. Matsuhisa T, Miki M, Yamada N, Sharma SK, Shrestha BM. Helicobacter pylori infection, glandular atrophy, intestinal metaplasia and topography of chronic active gastritis in the Nepalese and Japanese population: the age, gender and endoscopic diagnosis matched study. Kathmandu Univ Med J. 2007; 5(3): 295-301.

10. Singh V, Trikha B, Nain CK, Singh K et al. Epidemiology of Helicobacter pylori and peptic ulcer in India. J Gastroenterol Hepatol. 2002; 17:659-65.

11. Sonnenberg, A. Temporal trends and geographical variations of peptic ulcer disease. Aliment Pharmacol Ther. 1995; 9(Suppl 2): 3.

12. Anand, BS, Raed, AK, Malaty, HM, et al. Low point prevalence of peptic ulcer in normal individuals with Helicobacter pylori infection. Am J Gastroenterol. 1996; 91:1112.

13. Akdamar, K, Ertan, A, Agrawal, NM, et al. Upper gastrointestinal endoscopy in normal asymptomatic volunteers. Gastrointest Endosc. 1986; 32:78.

14. Lam SK, Hui WM, Ching CK. Peptic ulcer disease: epidemiology, pathogenesis and etiology. In: Haubrich WS, Schaffner F, Berk JE (eds). Bockus gastroenterology. 5th ed. Philadelphia : WB Saunders. 1994. p 700-48.

15. Schabowski J, Pitera J. Peptic ulcer among rural population in a selected region of southeastern Poland. Ann Agric Environ Med. 2004; 11:323-7.
16. Dong WG, Cheng CS, Liu SPet al. Epidemiology of peptic ulcer disease in Wuhan area of China from 1997 to 2002. World J Gastroenterol. 2004; 10:3377-9.

17. Korman MG, Hansky J, Eaves ER et al. Influence of cigarette smoking on healing and relapse in duodenal ulcer disease. Gastroenterology. 1983; 85: 871-4.

18. Chen TS, Chang FY, Lee SD. Smoking and male gender rather than CagA protein are associated with increased risk for duodenal ulcer in Helicobacter pylori-infected patients in Taiwan. Dig Dis Sci. 1999; 44: 2076-80.

19. Vu C, Ng YY. .Prevalence of Helicobacter pylori in peptic ulcer disease in a Singapore hospital. Singapore Med J. 2000; 41(10):478-81.

20. Wong, BC, Ching, CK, Lam, SK, et al. Differential north to south gastric cancerduodenal ulcer gradient in China. China Ulcer Study Group. J Gastroenterol Hepatol. 1998; 13:1050.

21. Kang, JY, Yeoh, KG, Ho, KY, et al. Racial differencesinHelicobacterpyloriseroprevalence in Singapore: Correlation with differences in peptic ulcer frequency. J Gastroenterol Hepatol. 1997; 12:655.

22. Kang JY, La Brooy SJ, Yap I, et al. Racial differences in peptic ulcer frequency in Singapore. J Gastroenterol Hepatol. 1987; 2: 239-44.

23. Tovey, FI, Hobsley, M, Kaushik, SP, et al. Duodenal gastric metaplasia and Helicobacter pylori infection in high and low duodenal ulcer-prevalent areas in India. J Gastroenterol Hepatol. 2004; 19:497. 